\title{
THE ASYMPTOTIC BEHAVIOR OF FREE ADDITIVE CONVOLUTION
}

\author{
HARI BERCOVICI AND JIUN-CHAU WANG
}

\begin{abstract}
We provide a new proof of the limit theorem for sums of free random variables in a general infinitesimal triangular array. This result was proved by Chistyakov and Götze using subordination functions. Our proof does not depend on subordination, and is close to the approach used in the case of arrays with identically distributed rows [5].
\end{abstract}

Mathematics subject classification (2000): 46L54, 60F05.

Key words and phrases: Free additive convolution; Limit theorems; Infinitesimal arrays.

\section{REFERENCES}

[1] O.E. BARNDORFF-NiElSEN AND S. THORbJøRNSEn, Self-decomposability and Lévy processes in free probability, Bernoulli 8 (2002), no. 3, 323-366.

[2] O.E. BARNDORFF-NIELSEN AND S. THORBJøRNSEN, A connection between free and classical infinite divisibility, Infin. Dimens. Anal. Quantum Probab. Relat. Top. 7 (2004), no. 4, 573-590.

[3] S.T. BELINSCHI AND H. BERCOVICI, Atoms and regularity for measures in a partially defined free convolution semigroup, Math. Z. 248 (2004), no. 4, 665-674.

[4] H. BERCOVICI AND V. PATA, The law of large numbers for free identical distributed random variables, Ann. Probab. 24 (1996), no. 1, 453-465.

[5] - Stable laws and domain of attraction in free probability, with an appendix by Ph. Biane, Ann. Math. 149 (1999), no. 3, 1023-1060.

[6] - A free analogue of Hinčin's characterization of infinite divisibility, Proc. Amer. Math. Soc. 128 (2000), no. 4, 1011-1015.

[7] H. BERCOVICI AND D.V. VoICUlesCu, Free convolution of measures with unbounded support, Indiana Univ. Math. J. 42 (1993), no. 3, 733-773.

[8] H. BERCOVICI AND JiUn-ChAU WANG, Limit theorems for free multiplicative convolutions, (2006), to appear in Trans. Amer. Math. Soc..

[9] PH. Biane, Processes with free increments, Math. Z. 227 (1998), no. 1, 143-174.

[10] G.P. CHISTYAKOV AND F. GÖTZE, Limit theorems in free probability theory I, Arxiv: math. OA/0602219.

[11] B.V. GNEDENKO AND A.N. KOLMOGOROV, Limit distributions for sums of independent random variables, Addison-Wesley Publishing Company, Cambridge, Massachusetts, 1954.

[12] A. HINČIN, Zur Theorie der unbeschränkt teilbaren Verteilungsgesetze, Mat. Sb. 2 (1937), 79-119.

[13] H. MAassen, Addition of freely independent random variables, J. Funct. Anal. 106 (1992), no. 2, 409-438.

[14] V. PATA, The central limit theorem for free additive convolution, J. Funct. Anal. 140 (1996), no. 2, 359-380.

[15] V.V. Petrov, Limit theorems of probability theory, Oxford Univ. Press, 1995.

[16] D.V. Voiculescu, Symmetries of some reduced free product $C^{*}$-algebras, Operator Algebras and their connections with Topology and Ergodic Theory (Buşteni, 1983). Lecture Notes in Math. 1132, Springer, Berlin, 1985, 556-588.

[17] —, Addition of certain noncommuting random variables, J. Funct. Anal. 66 (1986), no. 3, 323-346.

[18] - The analogues of entropy and of Fisher's information measure in free probability theory. I, Comm. Math. Phys. 155 (1993), no. 1, 71-92. 